\title{
Clinical outcomes of a cohort of patients with bulky, clinically node-positive bladder cancer undergoing radical cystectomy in the contemporary era
}

Jeffrey M. Howard; Vitaly Margulis; Solomon L. Woldu

Department of Urology, University of Texas Southwestern Medical Center, Dallas, TX, United States

Cite as: Howard JM, Margulis V, Woldu SL. Clinical outcomes of a cohort of patients with bulky, clinically node-positive bladder cancer undergoing radical cystectomy in the contemporary era. Can Urol Assoc J 2020 October 27; Epub ahead of print.

http://dx.doi.org/10.5489/cuaj.6966

Published online October 27, 2020

$* * *$

\section{Introduction}

Metastasis to regional lymph nodes is recognized as a poor prognostic factor in urothelial bladder cancer. Outcomes of patients with pathologically node positive $(\mathrm{pN}+)$ disease following radical cystectomy are well characterized, with 5-year overall survival (OS) rates of only 20-30\%. ${ }^{1,2}$ Studies of patients with clinically node positive $(\mathrm{cN}+)$ disease based on preoperative imaging have much more variable outcomes. For example, one recent series reported 5-year overall survival (OS) of over $50 \%$ in patients with $\mathrm{cN}+$ bladder cancer; whereas two other series based on cancer registry data reported 5-year OS rates of only $12-30 \%$ depending on treatment modality. ${ }^{3-5}$ These variations are due in part to criteria used to stage patients as $\mathrm{cN}+$. In one series which used short axis diameter $\geq 8 \mathrm{~mm}$ to define $\mathrm{cN}+$ status, over $50 \%$ of patients staged as $\mathrm{cN}+$ were found to be node-negative at surgery. ${ }^{4}$ Induction chemotherapy (ICT) prior to surgery improves outcomes in $\mathrm{cN}+$ disease. Failure to respond to ICT is an especially poor prognostic factor, with 5-year OS rates as low as $12-16 \% .{ }^{6,7}$ We have felt that patients with $\mathrm{cN}+$ disease and bulky (large or multiple) pelvic lymph nodes fare especially poorly. We sought to identify such a population within our practice and define their outcomes.

\section{Methods}

With IRB approval, we reviewed preoperative imaging reports of all patients undergoing radical cystectomy for bladder cancer at our institution from January 1, 2016 - December 31, 2019 to identify patients with $\mathrm{cN}+\mathrm{M} 0$ disease. This period was selected to coincide with the availability of immuno-oncology (IO) treatments as salvage therapy. Patients were defined as $\mathrm{cN}+$ if they had a single pelvic lymph node $\geq 1.5 \mathrm{~cm}$ in diameter or multiple pelvic lymph nodes $\geq 1.0 \mathrm{~cm}$ in diameter. These criteria were chosen based on our clinical experience, with a goal of identifying a subset of patients with bulky disease and a high probability of true $\mathrm{N}+$ status. Patients with 
distant metastatic disease, including those with lymph nodes $\geq 1.0 \mathrm{~cm}$ above the aortic bifurcation, were excluded. Our primary outcome was 2-year recurrence-free survival (RFS), starting from the date of surgery. Recurrence-free and overall survival (OS) were estimated using Kaplan-Meier curves. The log-rank test was used to compare survival between subgroups, with a two sided $p$ value $\leq 0.05$ deemed significant. Analyses were conducted using IBM SPSS Statistics version 27 (IBM, Armonk, New York, USA).

\section{Results}

A total of 612 patients underwent radical cystectomy during the study period, of whom 32 met our criteria for $\mathrm{cN}+\mathrm{M} 0$ disease. Demographic factors and medical history are summarized in Table 1, and clinical staging factors in Table 2. Patients had bulky pelvic lymph nodes with a median largest node size of $2.0 \mathrm{~cm}$ (IQR, $2.4-2.7)$. The majority of patients were staged as cN2-3. High rates of hydronephrosis (66\%) and variant histology (63\%) were noted. Most patients (84\%) initiated induction chemotherapy (ICT), of whom 89\% completed three or more cycles. Reasons for not receiving ICT included patient refusal in three cases and treating clinican's discretion in two cases; no patients were excluded from receiving chemotherapy on the basis of ineligibility. Two patients with disease progression after ICT received salvage IO before proceeding to cystectomy. All patients receiving ICT were restaged prior to surgery; nodal response to treatment is summarized in Table 2. Clinical complete response, defined as reduction in all pathologic nodes to $<1 \mathrm{~cm}$ diameter, occurred in $41 \%$ of cases. Perioperative parameters, pathologic outcomes, and 90-day complications are summarized in Table 3.

With regard to pathologic outcomes, complete pathologic response (pT0N0) was achieved in 5/32 (16\%) patients, all of whom had received $\geq 3$ cycles of ICT. Negative lymph nodes ( $\mathrm{pN} 0)$ were found in 11/32 (34\%) patients, of whom all but one had received ICT. More than half $(56 \%)$ of patients received additional treatment after surgery. Consistent with the patients' aggressive underlying disease, oncologic outcomes were poor (Figure 1). The 2-year recurrence-free survival (RFS) and overall survival (OS) rates were $37 \%$ and $42 \%$, respectively. Patients with negative lymph nodes ( $\mathrm{pN} 0$ ) or complete pathologic response (pT0N0) at surgery had significantly better outcomes (2-year RFS $72 \%$ for $\mathrm{pN} 0$ versus $18 \%$ for $\mathrm{pN}+$, log-rank $p=$ $0.005 ; 80 \%$ for $\mathrm{pT} 0 \mathrm{~N} 0$ versus $28 \%$ for $\mathrm{pT}+\mathrm{N}+$, log-rank $p=0.042$ ). All observed recurrences occurred within the first 12 months of surgery.

\section{Discussion}

Studies of patients with clinically node-positive bladder cancer have had widely varying outcomes. We sought to define the outcomes of a subset of patients with bulky $\mathrm{cN}+$ disease undergoing radical cystectomy in our practice. Our cohort was notable for a high proportion of variant histology and by high levels of adverse prognostic factors. We used 2-year recurrence free survival as a primary endpoint, which has been shown to be a good proxy for longer term outcomes. ${ }^{8}$ We noted a high rate of early recurrence, with a 2-year RFS rate of only $37 \%$. 
Overall survival at two years was similarly poor (42\%), despite a large proportion of patients receiving additional treatment. Consistent with prior reports, pathologic N0 status and complete response to ICT were strong predictors of improved outcomes ${ }^{4,6,9}$.

Our study is limited by its retrospective nature and small number of patients. Our analysis was confined to patients undergoing radical cystectomy, and it does not capture the outcomes of patients who presented as $\mathrm{cN}+$ and did not undergo surgery. Most patients (84\%) received ICT, and all of those who did not were clinically eligible for ICT. In light of reports that $25-50 \%$ of bladder cancer patients are chemo-ineligible, ${ }^{10}$ this observation suggests that our cohort represents a select subset of $\mathrm{cN}+$ patients and implies that chemo-ineligible patients who present with $\mathrm{cN}+$ disease are not being offered curative treatment.

In highlighting the outcomes of this cohort of patients with bulky $\mathrm{cN}+\mathrm{M} 0$ bladder cancer, we hope to draw attention to a population of patients who have limited treatment options and who suffer early, rapid recurrence of disease. It is possible that more aggressive initial treatment of these patients may improve outcomes. We anticipate clinical trials in this space in the years to come. 


\section{References}

1. Stein JP, Lieskovsky G, Cote R, et al: Radical cystectomy in the treatment of invasive bladder cancer: long-term results in 1,054 patients. J Clin Oncol 2001;19:666-75.

2. Hautmann RE, De Petriconi RC, Pfeiffer C, et al: Radical cystectomy for urothelial carcinoma of the bladder without neoadjuvant or adjuvant therapy: long-term results in 1100 patients. Eur Urol 2012;61:1039-47.

3. Galsky MD, Stensland K, Sfakianos JP, et al: Comparative effectiveness of treatment strategies for bladder cancer with clinical evidence of regional lymph node involvement. J Clin Oncol 2016;34:2627-35.

4. Moschini M, Mattei A, Cornelius J, et al: Surgical treatment for clinical node-positive bladder cancer patients treated with radical cystectomy without neoadjuvant chemotherapy. World J Urol 2018;36:639-44.

5. Staník M, Poprach A, Zapletalová M, et al: Comparison of different treatment modalities outcomes in clinically node-positive bladder cancer: analysis of a population-based cancer registry. Clin Genitourin Cancer 2019;17:e759-67.

6. Ho PL, Willis DL, Patil J, et al: Outcome of patients with clinically node-positive bladder cancer undergoing consolidative surgery after preoperative chemotherapy: the M.D. Anderson cancer center experience. Urol Oncol Semin Orig Investig 2016;34:59.e159.e8.

7. Ploussard G, Pradere B, Beauval J-B, et al: Survival outcomes of patients with pathologically proven positive lymph nodes at time of radical cystectomy with or without neoadjuvant chemotherapy. J Clin Med 2020;9:1962.

8. Kim HS, Jeong CW, Kwak C, et al: Disease-free survival at 2 and 3 years is a significant early surrogate marker predicting the 5 -year overall survival in patients treated with radical cystectomy for urothelial carcinoma of the bladder. Front Oncol 2015;5:1-8.

9. Hermans TJN, Fransen van de Putte EE, Horenblas S, et al: Pathological downstaging and survival after induction chemotherapy and radical cystectomy for clinically nodepositive bladder cancer - results of a nationwide population-based study. Eur J Cancer 2016;69:1-8.

10. Dash A, Galsky MD, Vickers AJ, et al: Impact of renal impairment on eligibility for adjuvant cisplatin-based chemotherapy in patients with urothelial carcinoma of the bladder. Cancer 2006;107:506-513. 


\section{Figures and Tables}

Fig. 1. Oncological outcomes.
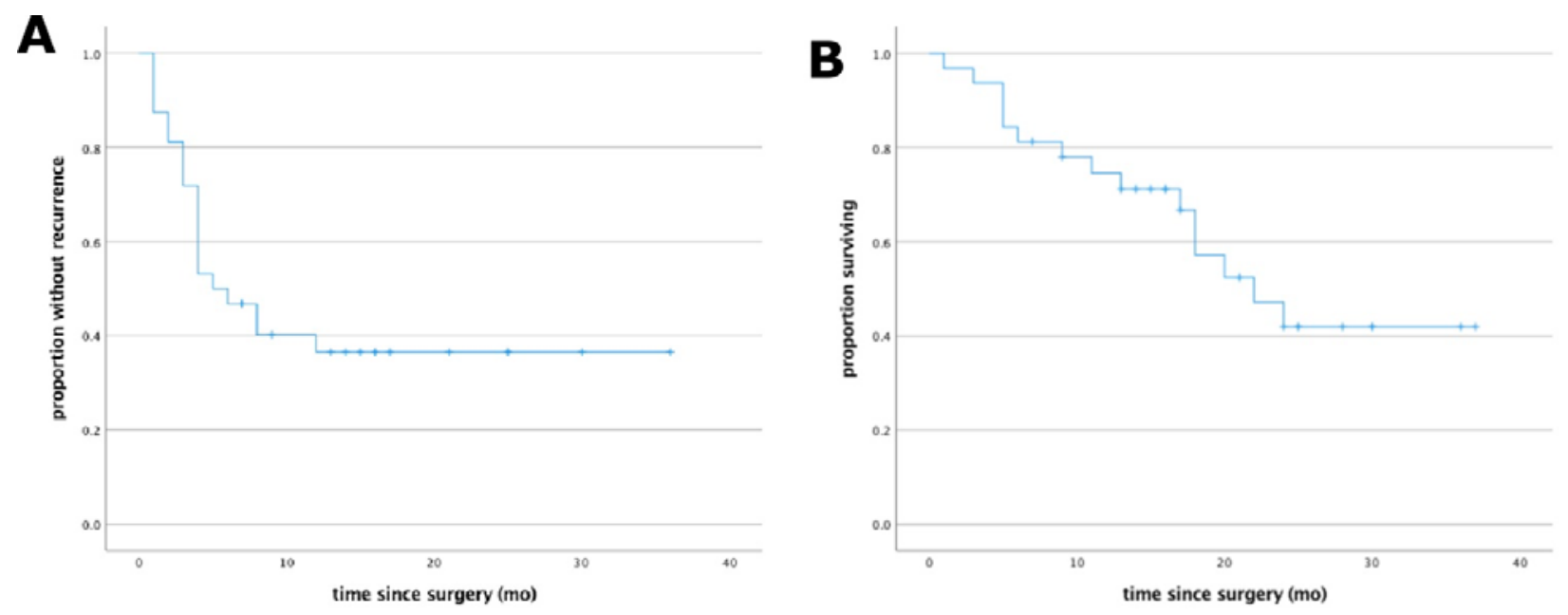

C
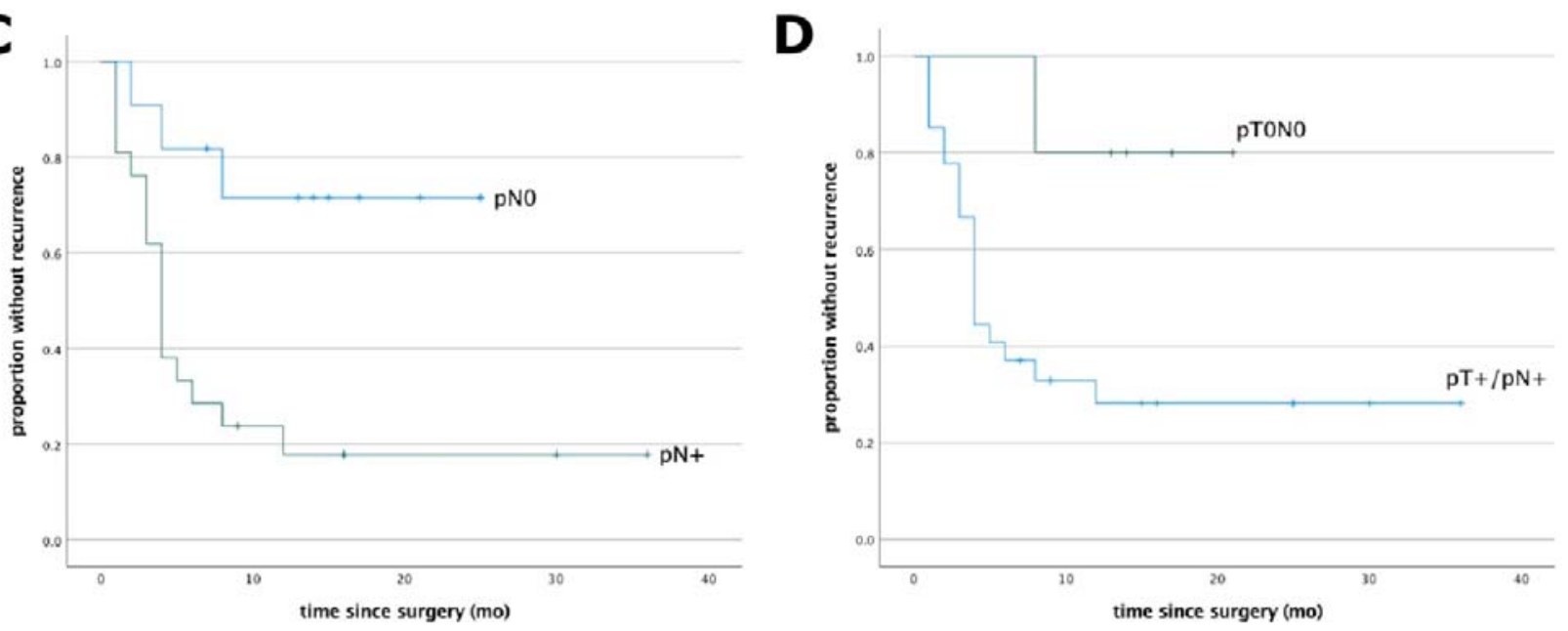


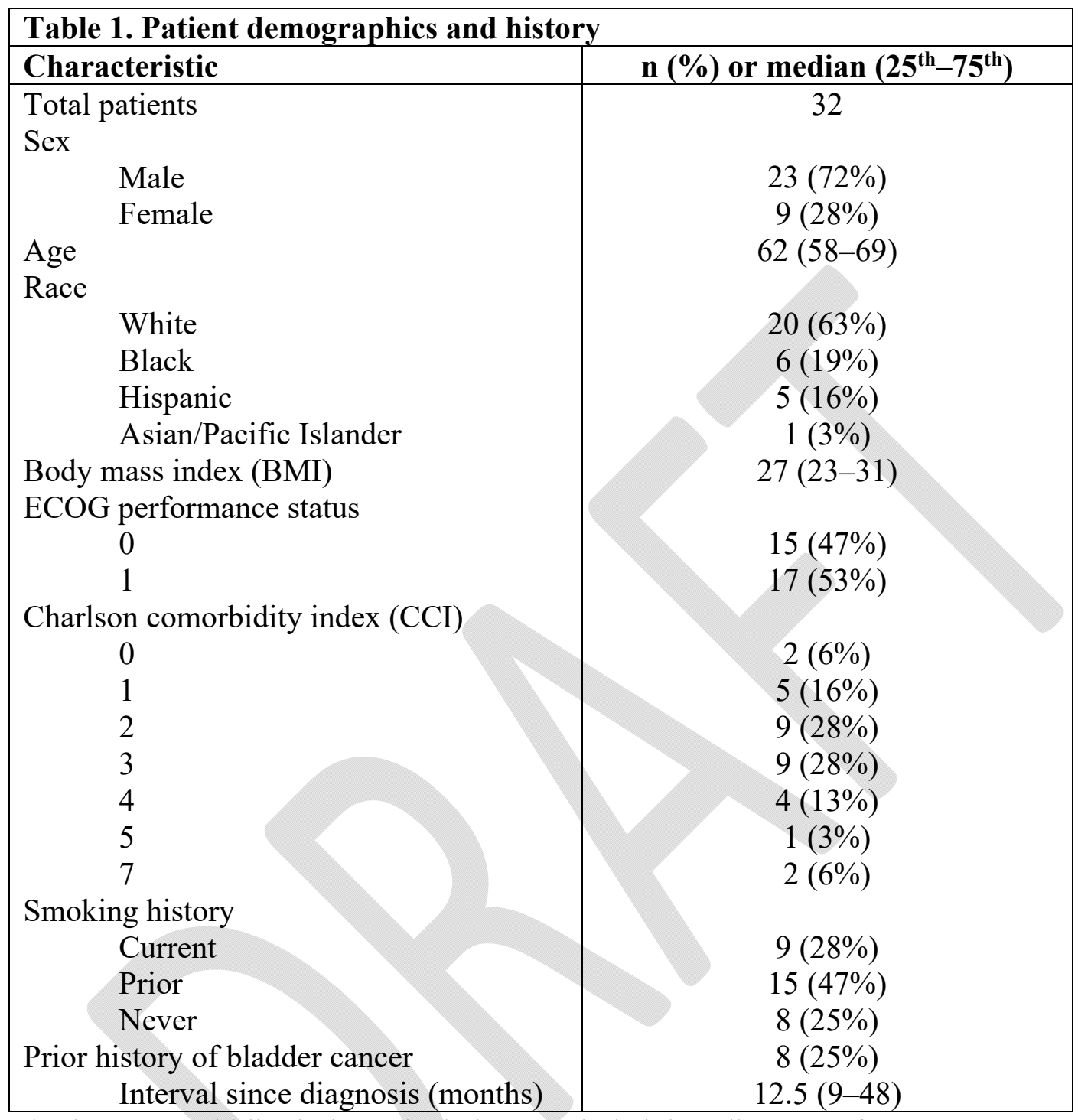

Charlson comorbidity index calculations excluded the adjustment for concurrent malignancy. 


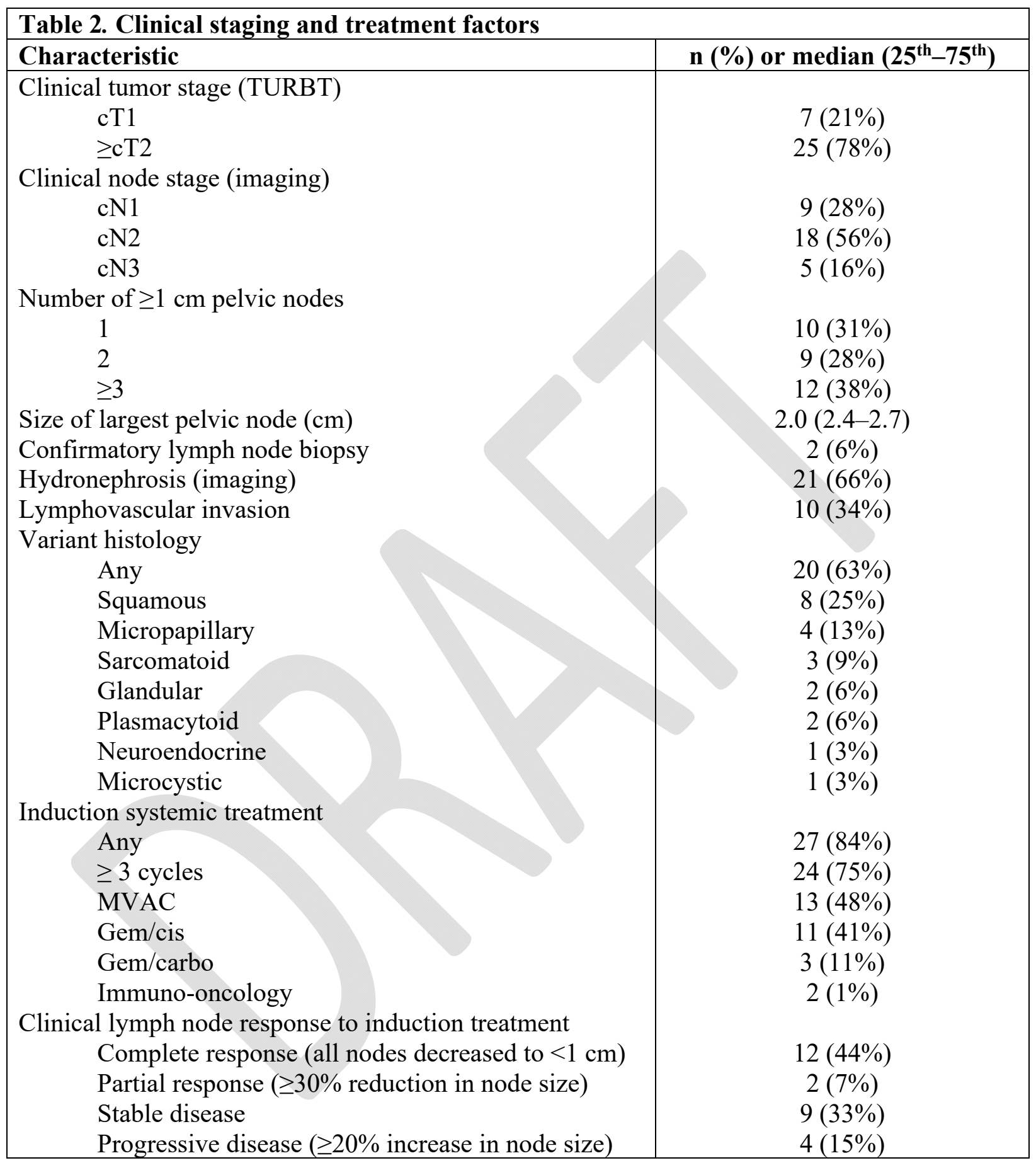

Data on lymphovascular invasion was not reported for three patients, resulting in a denominator of 29. Presence of variant histology is based on consensus between pathology at TURBT and RC. Two patients with variant histology had mixed patterns (micropapillary/glandular and squamous/plasmacytoid) and were counted in two categories. Both patients who received immuno-oncology therapy had previously received chemotherapy. Definitions of complete response, partial response, and progressive disease were based on RECISTv1.1 criteria. 


\begin{tabular}{|c|c|}
\hline Characteristic & n $(\%)$ or median $\left(25^{\text {th }}-75^{\text {th }}\right)$ \\
\hline \multicolumn{2}{|l|}{ Surgical approach } \\
\hline Open & $17(53 \%)$ \\
\hline Robotic & $15(47 \%)$ \\
\hline Operative time ( $\mathrm{min}$ ) & $324(290-379)$ \\
\hline Estimated blood loss (mL) & $300(250-575)$ \\
\hline Postoperative length of stay (days) & $6(5-12)$ \\
\hline Total red blood cell transfused (units) & $0.5(0-2)$ \\
\hline Followup (months) & $17(9-24)$ \\
\hline \multicolumn{2}{|l|}{ 90-day complications } \\
\hline Minor (Clavien-Dindo grade 1-2) & $16(90 \%)$ \\
\hline Major (Clavien-Dindo grade 3-5) & $8(25 \%)$ \\
\hline meregency room visit & $12(38 \%)$ \\
\hline Re-admission & $8(25 \%)$ \\
\hline Re-operation & $1(3 \%)$ \\
\hline Death & $2(6 \%)$ \\
\hline \multicolumn{2}{|l|}{ Pathological stage } \\
\hline pT0 & $5(16 \%)$ \\
\hline pTis & $1(3 \%)$ \\
\hline pT1 & $1(3 \%)$ \\
\hline pT2 & $7(22 \%)$ \\
\hline pT3 & $12(38 \%)$ \\
\hline pT4 & $6(19 \%)$ \\
\hline$\leq \mathrm{pT} 1$ & $7(22 \%)$ \\
\hline$\geq \mathrm{pT} 2$ & $25(78 \%)$ \\
\hline $\mathrm{pNx}$ & $2(6 \%)$ \\
\hline $\mathrm{pN} 0$ & $11(34 \%)$ \\
\hline $\mathrm{pN} 1$ & $5(16 \%)$ \\
\hline $\mathrm{pN} 2$ & $12(38 \%)$ \\
\hline $\mathrm{pN} 3$ & $2(6 \%)$ \\
\hline$\geq \mathrm{pN} 1$ & $21(66 \%)$ \\
\hline pT0N0 (pathologic complete response) & $5(16 \%)$ \\
\hline \multicolumn{2}{|l|}{ Lymph node dissection } \\
\hline Total nodes & $13.5(8-20)$ \\
\hline Positive nodes & $1(0-2.8)$ \\
\hline \multicolumn{2}{|l|}{$\mathrm{R} 1$ resection } \\
\hline Any & $9(28 \%)$ \\
\hline Gross residual disease & $7(22 \%)$ \\
\hline Positive soft tissue margin & $4(13 \%)$ \\
\hline \multicolumn{2}{|l|}{ Adjuvant treatment } \\
\hline Any & $9(29 \%)$ \\
\hline Chemotherapy & $1(3 \%)$ \\
\hline Immuno-oncology & $7(23 \%)$ \\
\hline
\end{tabular}




\begin{tabular}{|c|c|}
\hline Radiation & $2(6 \%)$ \\
Salvage treatment & $13(42 \%)$ \\
Any & $6(19 \%)$ \\
Chemotherapy & $9(29 \%)$ \\
Immuno-oncology & $8(26 \%)$ \\
Radiation & \\
\hline
\end{tabular}

Of note, both patients staged as pNx had bulky, grossly positive nodal disease and were included in the calculation as $\geq \mathrm{pN} 1$. Data on subsequent treatment was not available for one patient. Adjuvant/salvage modalities do not sum to $100 \%$ because some patients received multiple treatments. 